\title{
Identification of the gene for $\beta$-fructofuranosidase from Ceratocystis moniliformis CMW 10134 and characterization of the enzyme expressed in Saccharomyces cerevisiae
}

\author{
Niël van Wyk ${ }^{1}$ Kim M Trollope ${ }^{1}$ Emma T Steenkamp², Brenda D Wingfield² and Heinrich Volschenk ${ }^{1 *}$
}

\begin{abstract}
Background: $\beta$-Fructofuranosidases (or invertases) catalyse the commercially-important biotransformation of sucrose into short-chain fructooligosaccharides with wide-scale application as a prebiotic in the functional foods and pharmaceutical industries.

Results: We identified a $\beta$-fructofuranosidase gene $(\mathrm{Cm} / \mathrm{NV}$ ) from a Ceratocystis moniliformis genome sequence using protein homology and phylogenetic analysis. The predicted 615 amino acid protein, CmINV, grouped with an existing clade within the glycoside hydrolase (GH) family 32 and showed typical conserved motifs of this enzyme family. Heterologous expression of the CmINV gene in Saccharomyces cerevisiae BY4742 $\Delta$ suc2 provided further evidence that $\mathrm{CmINV}$ indeed functions as a $\beta$-fructofuranosidase. Firstly, expression of the CmINV gene complemented the inability of the $\triangle$ suc2 deletion mutant strain of $S$. cerevisiae to grow on sucrose as sole carbohydrate source. Secondly, the recombinant protein was capable of producing short-chain fructooligosaccharides (scFOS) when incubated in the presence of $10 \%$ sucrose. Purified deglycosylated CmINV protein showed a molecular weight of ca. $66 \mathrm{kDa}$ and a $K_{\mathrm{m}}$ and $V_{\max }$ on sucrose of $7.50 \mathrm{mM}$ and $986 \mu \mathrm{mol} / \mathrm{min} / \mathrm{mg}$ protein, respectively. Its optimal $\mathrm{pH}$ and temperature conditions were determined to be 6.0 and $62.5^{\circ} \mathrm{C}$, respectively. The addition of $50 \mathrm{mM} \mathrm{LiCl}$ led to a $186 \%$ increase in CmINV activity. Another striking feature was the relatively high volumetric production of this protein in S. cerevisiae as one $\mathrm{mL}$ of supernatant was calculated to contain $197 \pm 6$ International Units of enzyme.
\end{abstract}

Conclusion: The properties of the CmINV enzyme make it an attractive alternative to other invertases being used in industry.

Keywords: $\beta$-fructofuranosidase, Short-chain fructooligosaccharides, Ceratocystis moniliformis, Saccharomyces cerevisiae, Heterologous expression

\section{Background}

Invertases ( $\beta$-D-fructofuranosidases, EC 3.2.1.26), widely distributed among plants and microorganisms, catalyse the hydrolysis of sucrose to equimolar amounts of D-fructose and D-glucose [1]. At saturated (high) sucrose concentrations, many $\beta$-fructofuranosidases - especially those of fungal origin - display varying degrees of fructosyltransferase activity by cleaving the $\beta-(2 \rightarrow 1)$ linkage,

\footnotetext{
* Correspondence: volschenkh@sun.ac.za

'Department of Microbiology, Stellenbosch University, Room A322, JC Smuts Building, De Beer Street, Private Bag X1, Matieland 7602 Stellenbosch, South Africa

Full list of author information is available at the end of the article
}

releasing glucose, and transferring the fructose moiety onto an acceptor molecule other than water. These acceptor molecules are initially usually unhydrolysed sucrose (GF) which generates 1-kestose (GF2), whereafter another fructose moiety can be transferred onto 1-kestose to produce 1-nystose (GF3). This fructosyltransferase reaction can continue onto 1 -nystose to produce $1^{\mathrm{F}}$-fructofuranosylnystose (GF4) [2].

Collectively known as short-chain fructooligosaccharides (scFOS), mixtures of GF2-GF4 are considered as health-promoting food ingredients [3]. ScFOS have a lower sweetness intensity than sucrose making it suitable 
as a diabetic-friendly sweetener with low caloric and non-cariogenic properties. More importantly, scFOS function as prebiotic compounds that selectively stimulate beneficial colonic bifidobacteria and lactobacilli [4]. As a dietary additive they exert an array of beneficial effects on human health ranging from protection against the development of colon cancer and inflammatory bowel disease, improved calcium absorption, reduction of serum lipids and diminishing adverse effects of intestinal pathogens [3].

Furthermore, $\beta$-fructofuranosidases are currently also being investigated as potential biosensors for the detection of various biologically and medically relevant compounds $[5,6]$. In general, this application relies on the targetinduced release of a $\beta$-fructofuranosidase moiety from a functional DNA-enzyme conjugate. $\beta$-Fructofuranosidases are preferred above other types of enzymes due to the relatively inexpensive substrate, easily detectable endproducts and high catalytic activities of many fungal $\beta$-fructofuranosidases. For this reason it is desirable to produce high levels of $\beta$-fructofuranosidases in pure form.

$\beta$-Fructofuranosidases belong to the glycoside hydrolase family 32 (GH32) of the sequence-based classification of carbohydrate-active enzymes [7]. This family of enzymes also includes enzymes that exhibit activity on fructan-based carbohydrates like inulinases (EC 3.2.1.7), levanase (EC 3.2.1.65), exo-inulinase (EC 3.2.1.80), transfructosidases like sucrose:sucrose 1-fructosyltransferase (EC 2.4.1.99) and fructan:fructan 1-fructosyltransferase (EC 2.4.1.100). Members of the GH32 enzyme family retain the anomeric configuration of the anomeric carbon by operating through a double displacement mechanism. In all $\beta$-fructofuranosidases, the catalytic amino acid residues are conserved in that an aspartic acid (D) residue conducts the nucleophilic attack and a glutamic acid (E) residue acts as the general catalytic acid/base. These two bases are often located within conserved regions known as the WMNDPNG and EC motifs, respectively. Another aspartic acid residue within a conserved RDP motif has been identified as the transition state stabilizer and forms part of what is known as the catalytic triad with the other two residues [8].

Based on the 3D-stuctures that have been resolved for GH32 enzymes, the N-terminal catalytic domains exhibit a $\beta$-propeller configuration, a feature shared with family GH68 (which contains bacterial fructan-active enzymes) and together these two families form the GH-J clan [9]. The GH32 enzymes that have been described have bimodular arrangements and usually also have a Cterminal $\beta$-sandwich domain, which seems to maintain structural stability and may have a role in protein oligomerization [10].
A growing demand for scFOS as food and pharmaceutical ingredient combined with the inherent limitations of available enzymes used in the commercial production of scFOS from sucrose have been the driving force behind extensive research efforts to develop costeffective production and application of $\beta$-fructofuranosidases [11]. Here we describe the molecular, phylogenetic, and biochemical characterization of the first extracellular $\beta$-fructofuranosidase, CmINV, from the fungus Ceratocystis moniliformis (strain CMW 10134) recombinantly produced at high levels in an invertase-negative strain of S. cerevisiae.

\section{Results}

\section{Cloning of CmINV and fopA genes}

The primers designed in this study correctly amplified the CmINV gene from genomic DNA of C. moniliformis. For heterologous expression of the CmINV gene, no cDNA isolation of the gene was required as the gene contained no predicted introns. Functionality of the CmINV gene was confirmed in S. cerevisiae BY4742 as the gene complemented the suc2 gene knock-out that prohibits the strain from growing on sucrose as sole carbohydrate source. The synthetically-made fop $A$ gene also complemented the suc2 gene knock-out when expressed in S. cerevisiae BY4742, as reported previously [12].

In silico translation of the CmINV reading frame obtained revealed a corresponding 615 amino acid polypeptide with a calculated molecular mass of $65.7 \mathrm{kDa}$. The first 19 residues of the translated sequence comprised a eukaryotic secretion signal. In addition, the sequence of the mature protein had a predicted pI of 4.77 and seven putative $\mathrm{N}$-glycosylation sites were also identified on the mature sequence.

\section{Alignment and phylogeny}

Alignment of the CmINV amino acid sequence with known invertases revealed that the $C m I N V$ gene encodes a product with the expected conserved motifs reported for other invertases and members of the glycoside hydrolase family 32 (Figure 1). Based on these alignments, the residues D66, D205 and E283 of the translated protein sequence, were identified as the nucleophile, transition-state stabilizer and general acid/base catalyst, respectively. The WMNDPNG conserved region which includes the nucleophilic residue differs slightly in that the last two residues are CA instead of NG. However, the CmINV sequence has more homology to this region than other $\beta$-fructofuranosidases with known strong fructosyltransferase activities like fopA, Suc1 from A. niger [13] and F1 from Aspergillus oryzae [14]. Within the existing phylogenetic framework for the GH32 family [15], the CmINV protein sequence was grouped in a well- 


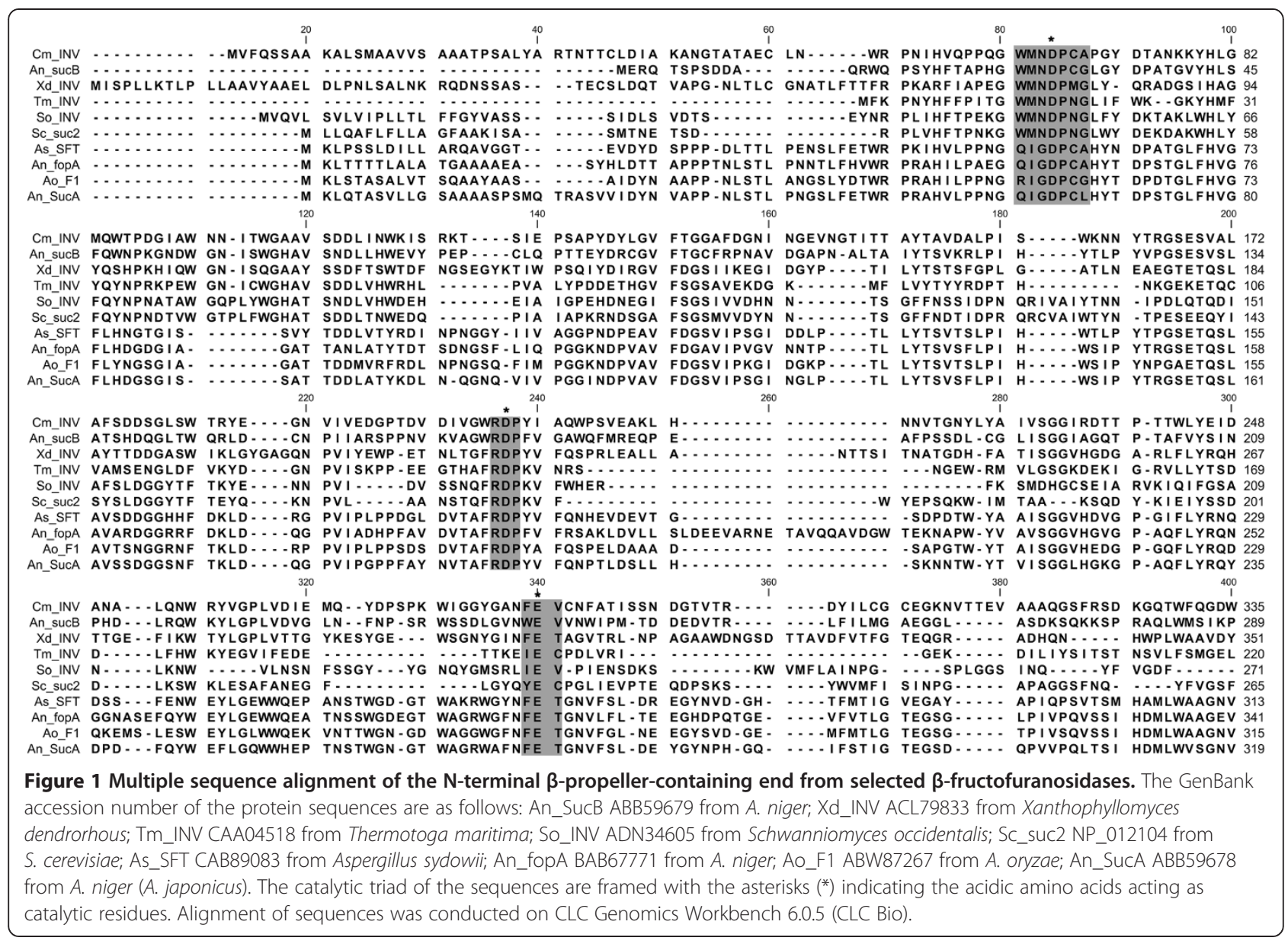

supported clade which was previously designated as the Group 8 intracellular invertase subfamily (Figure 2). The closest related protein (with $28.4 \%$ amino acid identity) to CmINV that has been characterized previously is the intracellular $\beta$-fructofuranosidase, SucB, of Aspergillus niger [16].

\section{Purification of $\mathrm{CmINV}$ and kinetic parameters}

Following size-exclusion chromatography of the crude yeast supernatant, electrophoretically homogenous $\beta$ fructofuranosidase-positive fractions were used for further characterization (see Additional file 1). Initial rate enzyme reactions of CmINV with increasing sucrose concentrations led to typical Michaelis-Menten-like kinetics with the apparent Michaelis constant $\left(K_{\mathrm{m}}\right)$ and maximal reaction velocity $\left(V_{\max }\right)$ parameters calculated to be $7.50 \mathrm{mM}$ and $986 \mu \mathrm{mol} / \mathrm{min} / \mathrm{mg}$ protein, respectively.

\section{Influence of temperature and $\mathrm{pH}$ on CmINV hydrolytic activity}

Purified CmINV was assayed for five minutes at various temperature and $\mathrm{pH}$ conditions simultaneously. The highest hydrolytic activity was recorded at a temperature of $62.5^{\circ} \mathrm{C}$ and a pH of 6.0 (Figure 3). Although CmINV hydrolytic activity could be detected at all the temperatures tested, no activity could be detected below pH 4.0. For thermostability analyses, the purified enzyme was preincubated at different temperatures for up to 24 hours before a five minute assay at $60^{\circ} \mathrm{C}$ was performed to generate a thermostability profile of the purified CmINV (Figure 4). CmINV did not retain any activity after 24 hours of incubation at temperatures over $40^{\circ} \mathrm{C}$. Of note is that activity of the enzyme was already lost after 30 minutes of incubation at $60^{\circ} \mathrm{C}$, which is just under its optimal temperature.

\section{Influence of ions on CmINV hydrolytic activity}

The addition of $\mathrm{Li}^{+}, \mathrm{Fe}^{3+}$ and $\mathrm{Co}^{2+}$ ions at a concentration of $5 \mathrm{mM}$ slightly increased CmINV hydrolytic activity (Table 1). However, a $186 \%$ increase in CmINV hydrolytic activity was observed in the presence of $50 \mathrm{mM} \mathrm{Li}^{+}$ions. In all other cases, the treatments with ions led to a reduction in CmINV hydrolytic activity. The addition of $50 \mathrm{mM} \mathrm{NH}_{4}{ }^{+}, \mathrm{Zn}^{+}$and $\mathrm{Mg}^{2+}$ completely inactivated the enzyme. 


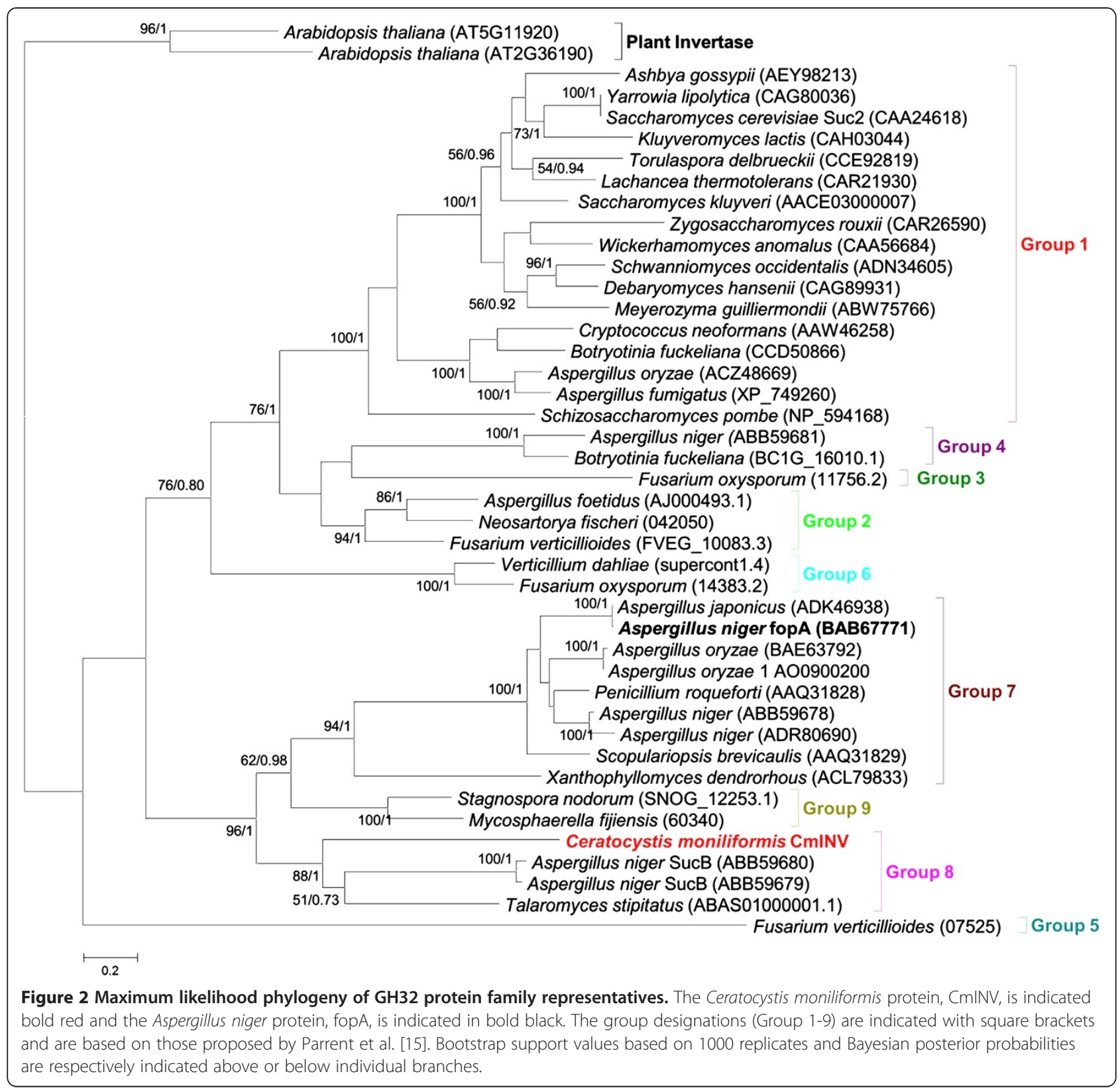

\section{ScFOS production}

Crude CmINV was capable of producing both 1-kestose and traces of 1-nystose from 10\% sucrose under the experimental conditions (Figure 5). Its $\mathrm{U}_{\mathrm{t}} / \mathrm{U}_{\mathrm{h}}$ ratio i.e. fructosyltransferase to hydrolase activity was calculated to be 0.92 . This was less than the $U_{t} / U_{h}$ ratio of 1.50 of fopA under the same conditions.

\section{Electrophoresis and zymogram analyses}

SDS-PAGE of S. cerevisiae BY4742[CmINV] supernatant showed a distinct band larger than $200 \mathrm{kDa}$ (Figure 6). This band showed invertase activity when the same sample was subjected to zymogram analysis. De- $N$ - glycosylation of the supernatant revealed a protein band (estimated at $66 \mathrm{kDa}$ ) corresponding to the predicted molecular size of the mature protein of $65.6 \mathrm{kDa}$. Despite several alterations to the protocol, the de- $\mathrm{N}$ glycosylated version of CmINV showed no activity upon zymogram analysis.

\section{Small-scale recombinant production of CmINV and fopA enzymes}

Supernatants of $S$. cerevisiae BY4742[CmINV] cultivated in $50 \mathrm{~mL}$ of SC media in $250 \mathrm{~mL}$ Erlenmeyer flasks for two days were calculated to produce $197 \pm 6$ IU of $\mathrm{CmINV}$ enzyme when assayed for five minutes at $60^{\circ} \mathrm{C}$. 


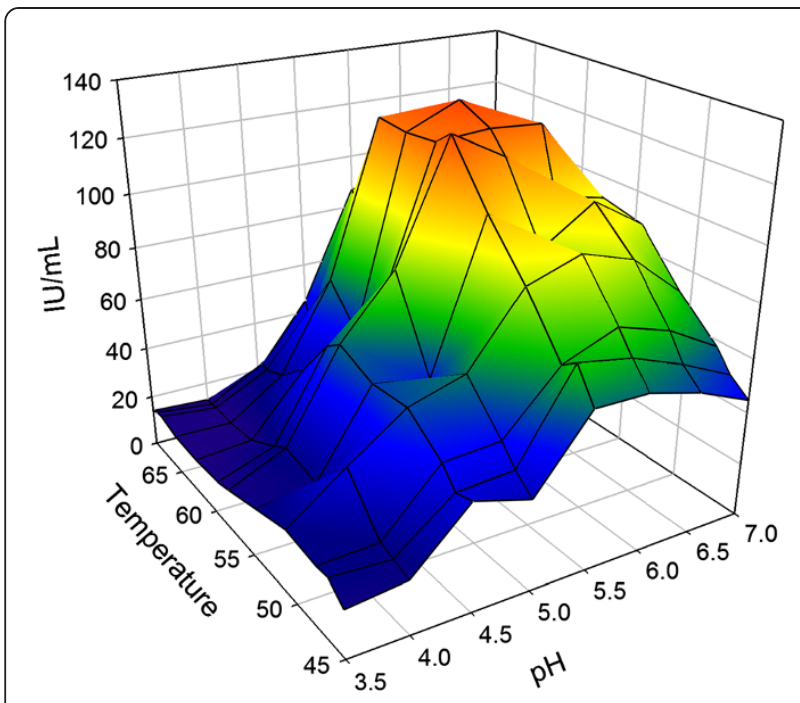

Figure 3 3D-mesh plot representing $\mathrm{pH}$ and temperature optimum conditions of CmINV activity on sucrose. Five minute assays were conducted using yeast culture supernatant incubated with $50 \mathrm{mM}$ sucrose at temperatures ranging from $35-69^{\circ} \mathrm{C}$ and different $\mathrm{pH}$ values. Volumetric units $\mathrm{IU} / \mathrm{mL}$ were defined as the amount of enzyme per millilitre producing 1 umole of product per minute.

In comparison, only $2.1 \pm 0.5 \mathrm{IU}$ of enzyme of $S$. cerevisiae BY4742[fopA] was produced under the same cultivation conditions by the yeast.

\section{Discussion}

The bioconversion of sucrose by $\beta$-fructofuranosidases from Aspergillus niger or Aureobasidium pullulans is one of the current methods used in commercial scFOS
Table 1 Influence of several metal ions on purified CmINV activity \pm SE values

\begin{tabular}{lll}
\hline Ion present & \multicolumn{2}{l}{ Percentage activity retained } \\
\cline { 2 - 3 } & $\mathbf{5} \mathbf{~} \mathbf{M}$ & $\mathbf{5 0} \mathbf{~ m M}$ \\
\hline None & $100 \%$ & $100 \%$ \\
$\mathrm{CaCl}_{2}$ & $86 \pm 6 \%$ & $29 \pm 2 \%$ \\
$\mathrm{CoCl}_{2}$ & $118 \pm 1 \%$ & $51 \pm 1 \%$ \\
$\mathrm{FeCl}_{3}$ & $137 \pm 7 \%$ & $34 \pm 2 \%$ \\
$\mathrm{LiCl}$ & $119 \pm 2 \%$ & $186 \pm 2 \%$ \\
$\mathrm{MgCl}_{2}$ & $94 \pm 6 \%$ & $5 \pm 5 \%$ \\
$\mathrm{NH}_{4} \mathrm{Cl}$ & $105 \pm 16 \%$ & $4 \pm 0 \%$ \\
$\mathrm{NiCl}_{2}$ & $47 \pm 2 \%$ & $18 \pm 2 \%$ \\
$\mathrm{ZnCl}_{2}$ & $80 \pm 18 \%$ & $4 \pm 3 \%$ \\
\hline $\mathrm{Stan}^{2}$
\end{tabular}

"Standard five minute assays were conducted at $62.5^{\circ} \mathrm{C}$ and $\mathrm{pH} 6$ using two different ion concentrations.

production [17]. With the increasing demand for scFOS in food and pharmaceutical products, efforts to find alternative $\beta$-fructofuranosidases from other microbial sources or to increase enzyme production efficiency by known $\beta$-fructofuranosidase producers have been a major research thrust to lower scFOS production costs [18].

The recent availability of the complete genome sequence (unpublished) of C. moniliformis CMW 10134 facilitated the identification the $C m I N V$ gene, which encodes a $\beta$-fructofuranosidase. Phylogenetic analysis of this protein revealed that it forms part of a clade (Group 8) containing other known and putative $\beta$-fructofuranosidases [15]. Within Group 8, CmINV is closely related to the $\beta$-fructofuranosidase SucB of A. niger, although the members of Group 8 are thought to represent intracellular

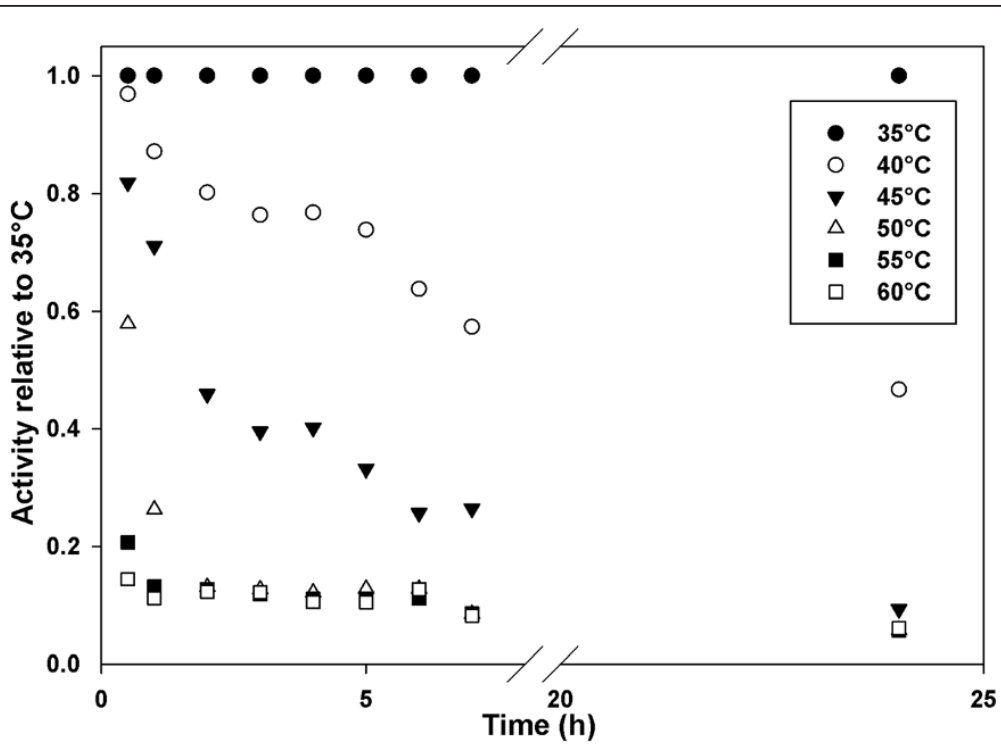

Figure 4 Thermostability activity profile of purified CmINV. Enzyme in $50 \mathrm{mM}$ citrate-phosphate buffer (pH 6) was preincubated at abovementioned temperatures and five microliters were removed at each time point. A standard five minute assay was conducted on the preincubated enzyme at $60^{\circ} \mathrm{C}$. Data points represent the average of quadruplicate assay values. 


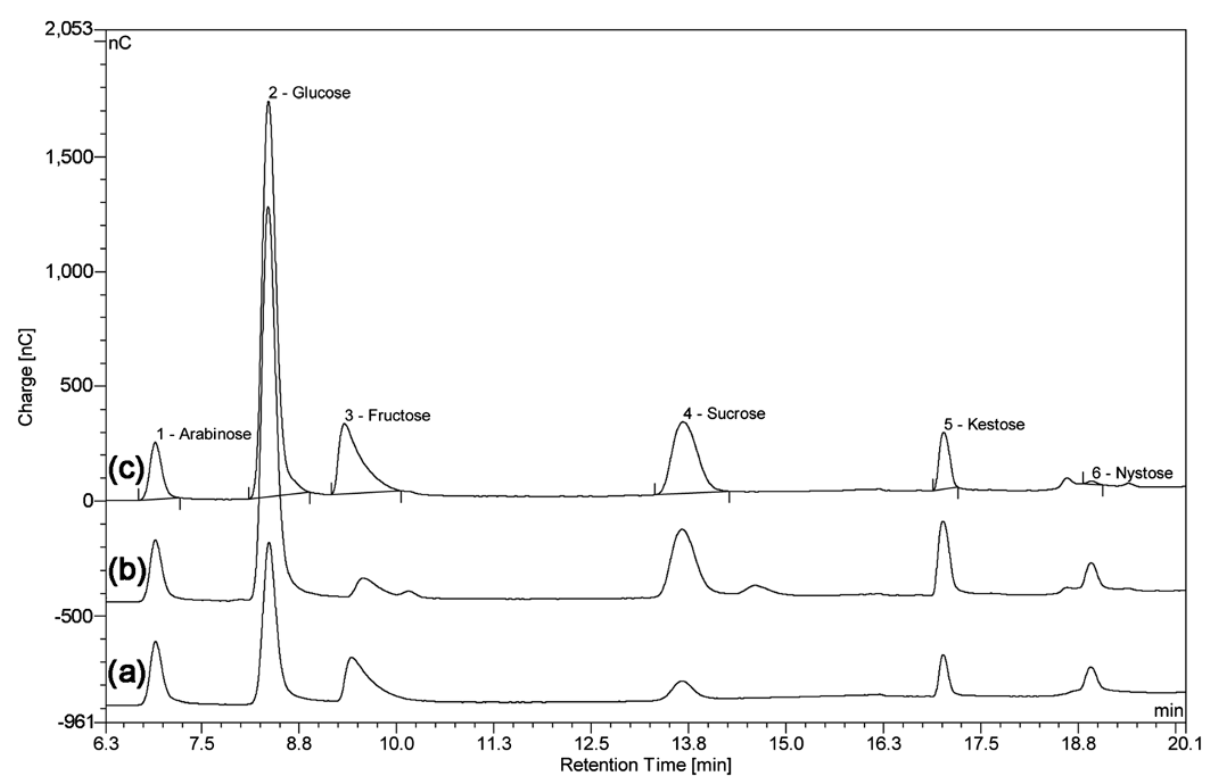

Figure 5 HPAEC chromatograms of sugars released from sucrose by fopA and CmINV enzymes. HPAEC chromatograms showing external standards (a) and products from the incubation of fopA (b) and CmINV (c) enzymes (1 IU) with $50 \mathrm{mM}$ sucrose in 50 mM citrate phosphate buffer ( $\mathrm{pH}$ 6) for 60 minutes. Samples (b and $\mathbf{c}$ ) shown here were diluted 1000x from the original reaction.

(a)

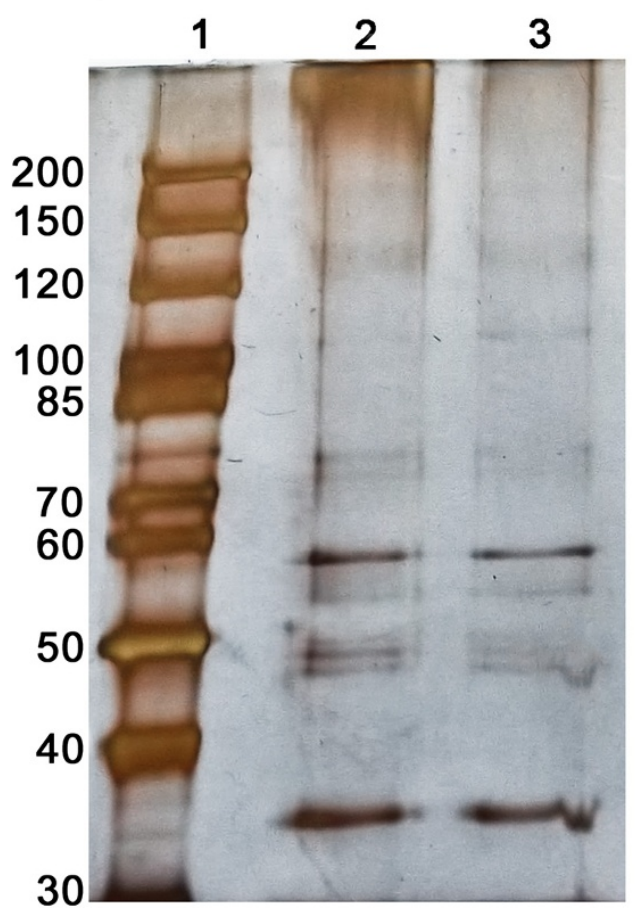

(b)

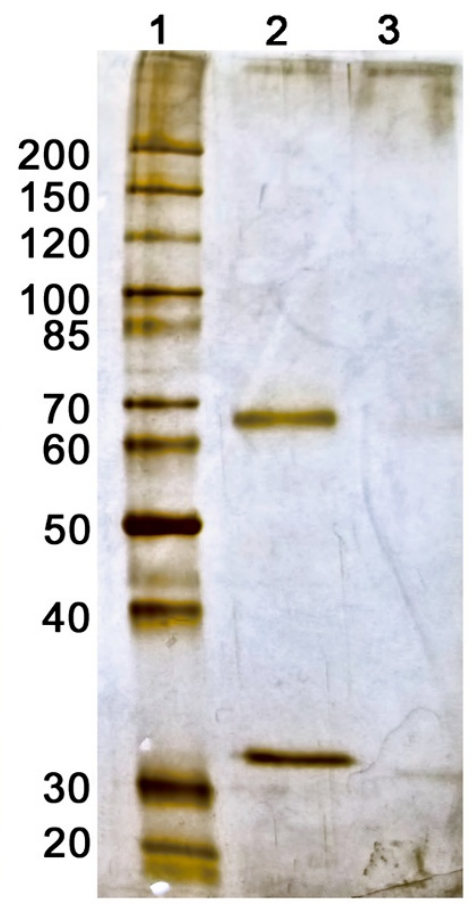

(c)

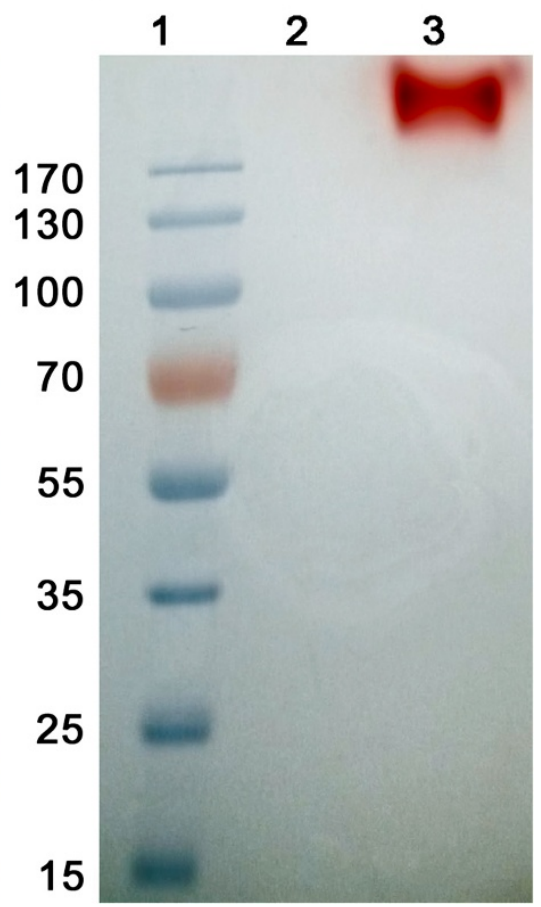

Figure 6 SDS-PAGE and zymogram gels of CmINV. (a) Silver-stained 10\% polyacrylamide gel of crude extract of S. cerevisiae BY4742[CmINV] in lane 2. Lane 3 is a reference S. cerevisiae BY4742[pJC1] strain containing the empty vector pJC1. (b) Silver-stained 10\% polyacrylamide gel of purified CmINV. Lane 2 contains the de-N-glycosylated version (lower band corresponds to PNGase F). Lane 3 contains the un-de-N-glycosylated version of purified CmINV. (c) Zymogram gel of purified CmINV. Lanes were loaded similar to gel $\mathbf{b}$. The protein molecular weight markers PageRuler unstained Protein Ladder (lanes 1 in $\mathbf{a}$ and $\mathbf{b}$ ) and PageRuler Prestained Protein Ladder (Thermo Scientific) (lane 1 in $\mathbf{c}$ ) were used in SDS-PAGE and Zymogram analyses, respectively. 
invertases because of their apparent lack of signal peptide cleavage sites [16]. Like the commercially-used proteins fopA from A. niger and Suc2 from S. cerevisiae, CmINV harbours a signal peptide cleavage site between amino acids 19 and 20, supporting the fact that it is a secreted enzyme. Experimental data substantiate this claim, as $\beta$-fructofuranosidase activity was detected in the supernatant of S. cerevisiae. However, Suc2 and fopA respectively form part of Groups 1 and 7 that both include other extracellular fungal invertases [14]. These data thus suggest that, in the case of the GH32 family, phylogenetic affinity alone has little predictive value regarding subcellular localization.

Since non-sucrolytic strains of $S$. cerevisiae have previously been shown to be ideal expression hosts for $\beta$-fructofuranosidase genes $[12,16], S$. cerevisiae BY4742 $\Delta s u c 2$ was used for the heterologous expression of the CmINV gene for ease of characterization of the protein. CmINV was purified from the supernatant of the recombinant yeast with size-exclusion chromatography. Since S. cerevisiae produces few extracellular proteins and the CmINV protein appeared electrophoretically homogenous on a silver-stained PAGE-gel, additional purification was not necessary for subsequent characterization of the protein. CmINV acts as a $\beta$ fructofuranosidase, which is able to hydrolyse the glucosefructose glycosidic linkage in sucrose. CmINV appears to have a relatively high affinity for sucrose with an experimentally determined the $K_{\mathrm{m}}$ value of the purified CmINV for sucrose $(7.50 \mathrm{mM})$ lower than what has been reported for the widely-used industrial invertase of $S$. cerevisiae, Suc2 [19-21]; Lafraya et al. [22] recently reported the $K_{\mathrm{m}}$ of $38 \mathrm{mM}$ for Suc2, although varying $K_{\mathrm{m}}$ values for Suc2 ranging from 9.1 to $61.2 \mathrm{mM}$ have been reported. The $\left(V_{\max }\right)$ of CmINV for sucrose as substrate was $986 \mu \mathrm{mol} /$ $\mathrm{min} / \mathrm{mg}$ which is about 150 times higher than that for its closest characterized relative i.e. the SucB of $A$. niger with a $V_{\max }$ of $6.6 \mu \mathrm{mol} / \mathrm{min} / \mathrm{mg}$ [16]. Calculation of the turnover rate $\left(\mathrm{k}_{\mathrm{cat}}\right)$ of the enzyme was not done due to the high level of recombinant glycosylation of CmINV, making accurate molecular weight determination misleading.

CmINV retained $75 \%$ of its hydrolytic activity observed under optimal $\mathrm{pH}$ and temperature conditions at $\mathrm{pH}$ levels of 5.5-6.5 and temperatures of $50-65^{\circ} \mathrm{C}$. Although its closest characterized relative, the intracellular SucB of $A$. niger, possesses a similar $\mathrm{pH}$ optima profile, its temperature optima was only recorded at $37-40^{\circ} \mathrm{C}$ [16]. A characteristic that CmINV shares with Suc2 is its weak thermostability after prolonged exposure to higher-than-ambient temperatures [23]. A more thermostable version of an enzyme is highly desirable as it would increase the productivity of enzyme conversion [24]. One way to improve the thermostability of CmINV could be to add bifunctional cross-linkers as had been done to improve the thermostability of Suc2 [23]. Immobilizing invertases on several hydrophilic matrices have also been shown in many cases to improve the general stability of the enzyme [25].

This study showed that CmINV produce significant amounts of scFOS from sucrose. However, based on the experimental conditions, the fructosyltransferase to hydrolysis ratio was found not to be as high as the commercially-used fopA enzyme. Optimization of the experimental conditions could improve the fructosyltransferase reaction of the CmINV enzyme and subsequent scFOS yields. Since there is a noticeable difference in homology between the conserved region which contains the nucleophilic aspartic acid of CmINV and fopA, mutations within this region might be key if improvement of the fructosyltransferase capability is desired. This strategy was employed with $S$. cerevisiae's Suc2 where most enhanced fructosyltransferase activity was observed when mutations were introduced within this conserved region [22].

Most of the metal ion additions to the enzyme reactions, with the exception of $\mathrm{Li}^{+}$, behaved predictably since most treatments had either a marginal improvement or negative impact [26,27]. To our knowledge, incorporating $\mathrm{Li}^{+}$ions to any invertase reaction has not yet been reported and it is still unclear why the large increase in activity was observed. No particular pattern could be observed with regards to the ionic radius of $\mathrm{Li}^{+}$ relative to the other ions tested as the sizes of ionic radii of ions have been reported to have a varying effect on many enzymatic reactions [27]. Monovalent salts such as $\mathrm{LiCl}$ generally modifies the ionic strength of a solution which, depending on the charge distribution of the enzyme, have either a stabilizing or destabilizing impact on the enzyme conformation [28]. Although $\mathrm{Ca}^{2+}, \mathrm{Mg}^{+}$and $\mathrm{Na}^{+}$additions were shown to enhance invertase activity previously [26,29], the opposite was found for CmINV. $\mathrm{Na}^{+}$additions were not conducted as the enzyme was already resuspended in $\mathrm{Na}^{+}$-containing PBS-buffer. Although ion additions clearly affect invertase activity, the results obtained from this study as well as from many previous reports indicate that no clear pattern exists to predict which ion will lead to a dramatic improvement or reduction in invertase activity.

Despite numerous theories, to predict at what levels a recombinant protein will be produced in its recombinant host is impossible [30,31]. This is mainly due to the complex interactions of all the factors that are involved in the successful production of any protein regardless whether it is foreign or not. Here, we show that the CmINV protein with its unmodified gene sequence can be produced at relatively high levels in S. cerevisiae. This is exemplified when compared to the fopA enzyme levels - functionally similar and expressed from a codon- 
optimized gene - that is produced at roughly 100-fold lower levels. This bodes well for possible large-scale application of CmINV and could provide an alternative to other invertases being used in industry.

To our knowledge, no other gene product from $C$. moniliformis has been characterized to any extent. Although the complete genome sequence of $C$. moniliformis CMW 10134 is not currently publicly available, this work highlights how gene discovery is facilitated in the exciting era of next-generation sequencing and the vast amounts of genomic data associated with it. By making use of reverse genetics approaches such as the one used in this study, a plethora of industrially functional products await discovery, not only in Ceratocystis but all of the thousands of fungi whose genomes are currently being sequenced (e.g. http://1000.fungalgenomes.org).

\section{Conclusions}

We described here the $\beta$-fructofuranosidase gene $(C m I N V)$ from $C$. moniliformis and the recombinant expression thereof in S. cerevisiae. The recombinant CmINV showed high affinity towards sucrose and along with its notable high-level production and secretion by $S$. cerevisiae makes this protein an attractive option for large-scale applications.

\section{Methods}

\section{Strains, culture conditions and DNA manipulations}

General procedures for cloning, DNA isolation, amplification and manipulations, transformations, agarose and protein gel electrophoresis were performed as described by Sambrook et al. [32]. Escherichia coli DH5 $\alpha$ served as a cloning host and for plasmid propagation and was routinely cultivated at $37^{\circ} \mathrm{C}$ in LB media $(10 \mathrm{~g} / \mathrm{L}$ tryptone, $10 \mathrm{~g} / \mathrm{L} \mathrm{NaCl}, 5 \mathrm{~g} / \mathrm{L}$ yeast extract) supplemented with $100 \mu \mathrm{g} / \mathrm{mL}$ ampicillin. The C. moniliformis genome sequence was derived from strain CMW 10134 (Fungal and Yeast Collection, Centraalbureau voor Schimmelcultures, WDCM no.: WDCM133, http://www.cbs.knaw.nl/) and used to identify and clone the $C m I N V$ gene. C. moniliformis CMW 10134, originally isolated from Eucalyptus grandis trees in South Africa [33], was cultured and maintained on Potato Dextrose Agar (PDA) (BD Difco). The SUC2 deletion strain of $S$. cerevisiae BY4742 (Mat $\alpha$; his $3 \Delta 1$; leu $2 \Delta 0$; lys $2 \Delta 0$; ura $3 \Delta 0$; YIL162w::kanMX4) (EUROSCARF collection) [33,34] was used for the heterologous expression of the CmINV gene. Transformed $S$. cerevisiae BY4742 cells were cultivated aerobically at $30^{\circ} \mathrm{C}$ shaken at $200 \mathrm{rpm}$ in synthetic complete (SC) media containing $6.7 \mathrm{~g} / \mathrm{L}$ yeast nitrogen base, $1.3 \mathrm{~g} / \mathrm{L}$ amino acid pool without uracil and $20 \mathrm{~g} / \mathrm{L}$ glucose (referred to $\mathrm{SC}_{\mathrm{Gluc}}$ from here on) or sucrose (referred to $\mathrm{SC}_{\mathrm{Suc}}$ from here on). $\mathrm{SC}$ media was also buffered with $20 \mathrm{~g} / \mathrm{L}$ succinic acid, $\mathrm{pH}$ adjusted to 6.0 with $10 \mathrm{~N} \mathrm{NaOH}$ and with/without 1.5\% $(w / v)$ agar.

\section{CmINV gene identification and construction of S. cerevisiae expression vectors}

The genome sequence of C. moniliformis CMW 10134 was sequenced using 454 pyrosequencing technology at Inqaba Biotechnology (Roche Diagnostics). Sequence reads were assembled into 600 contigs using Newbler version 2.3 then subjected to local BLAST searches to identify the contig encoding the $C m I N V$ gene. This was done using the Aspergillus niger (recently renamed Aspergillus japonicus [15]) ATCC 20611 fopA amino acid sequence (GenBank accession no. BAB67771) and BioEdit (http://www.mbio.ncsu.edu/BioEdit/bioedit.html). By making use of the online annotation programme AUGUSTUS [35] one open reading frame of $1848 \mathrm{bp}$ was identified within this contig as having $\beta$-fructofuranosidase-like domains. The predicted amino acid sequence for $C m I N V$ was compared to the NCBI database using BLASTp, while SignalP 4.0 (www.cbs.dtu.dk/services/ SignalP/) and NetNGlyco 1.0 (www.cbs.dtu.dk/services/ NetNGlyc/) were used to analyse the relevant features of the predicted protein sequence.

Genomic DNA extracted from fresh C. moniliformis CMW 10134 mycelia grown on PDA was used to amplify the CmINV gene [36]. The primers CmINV-F (5'ACTGTTAATTAAGAATTCATGGTTTTCCAATCTTC TGC-3') and CmINV-R (5'-ACTGGAATTCGGCGCG CCTTACTCAATGTAAGTCAGAG-3') were designed to amplify the CmINV coding region (start and stop codons in bold) based on the CmINV genomic sequence to include targets for the EcoRI restriction enzyme (bold italicised) as well as auxiliary targets for PacI (in CmINV-F) and $A s c$ I (in CmINV-R) restriction enzymes (italicised). PCR amplification was conducted using the Phusion High-Fidelity PCR polymerase (Thermo Scientific) according to the manufacturer's instructions in a MultiGene $^{\mathrm{Tm}}$ Gradient PCR Thermal Cycler (Labnet). The 1850-bp amplicon was digested with EcoRI and ligated with T4 ligase (Thermo Scientific) into an EcoRI-digested E. coli/S. cerevisiae shuttle vector pJC1 (containing the constitutive $S$. cerevisiae phosphoglycerate kinase 1 (PGK1) promoter and terminator cassette) [37].

The fopA gene encoding an Aspergillus niger ATCC $20611 \beta$-fructofuranosidase (GenBank accession no. AB046383) was synthesized by GeneArt (Regensburg, Germany) and used as a positive control during $\beta$ fructofuranosidase expression studies in $S$. cerevisiae. The fop $A$ native secretion signal was replaced by the Trichoderma reesei endo- $\beta-1,4$-xylanase 2 (Xyn11A) secretion signal. This synthetic construct was subcloned as a 2033-bp EcoRI-XhoI fragment from the in-house pMK- 
RQ cloning vector to the EcoRI-XhoI digested pJC1 vector.

The pJC1-CmINV, pJC1-fopA plasmids and the empty pJC1 vector were transformed into the $S$. cerevisiae BY4742 strain using a lithium acetate-DMSO method [38]. S. cerevisiae BY4742[CmINV], BY4742[fopA] and BY4742[pJC1] transformants were confirmed with PCR. As an indication of $\beta$-fructofuranosidase functionality, the (in)ability of the $S$. cerevisiae BY4742[CmINV], BY4742[fopA] and BY4742[pJC1] yeast transformants to grow on sucrose as sole carbohydrate source was performed on $\mathrm{SC}_{\mathrm{Suc}}$.

\section{Purification of CmINV}

The S. cerevisiae BY4742[CmINV] and BY4742[fopA] strains were grown in above mentioned $\mathrm{SC}_{\mathrm{Gluc}}$ media for three days. Two millilitres of supernatant were applied onto a Superose 12 HR 10/30 (GE Healthcare BioSciences) column equilibrated in phosphate-buffered saline buffer $\mathrm{pH}$ 6.5. The column was coupled to an Äkta FPLC purifier (Amersham Biosciences) and Unicorn version 4.00 software was used to process data. With a flow rate of $1 \mathrm{ml} / \mathrm{min}$, fractions of $500 \mu \mathrm{L}$ were taken after which samples were assayed for invertase activity and analysed on polyacrylamide gels. Further characterization was done on fractions that appeared electrophoretically homogenous after silver staining. For the determination of protein concentration of fractions, the Lowry-based DC protein assay kit (BioRad) was used. Bovine serum albumin at a concentration range of $0.247-1.48 \mathrm{mg} / \mathrm{mL}$ was used to construct a standard curve.

\section{Enzyme assays}

Enzyme assays were based on reducing sugars released from the cleavage of sucrose to fructose and glucose using the 3,5-dinitrosalicyclic acid (DNS) [39]. Assays were conducted in either triplicate or quadruplicate using a MultiGene $\mathrm{e}^{\mathrm{tm}}$ Gradient PCR Thermal Cycler (Labnet). In short, five microliters of appropriately diluted enzyme were added to $45 \mu \mathrm{L}$ of $50 \mathrm{mM}$ sucrose substrate and incubated at predetermined temperatures in the PCR thermocycler. The reaction was terminated after five minutes of incubation with the addition of a solution containing $1 \%$ DNS, $20 \%$ potassium sodium tartrate, $1 \% \mathrm{NaOH}, 0.2 \%$ phenol, and $0.05 \% \mathrm{Na}_{2} \mathrm{SO}_{3}$. The samples were then boiled for five minutes and the colour reaction recorded spectrophotometrically at $540 \mathrm{~nm}$. International units (IU) of enzyme were defined as the amount of product (in $\mu$ mole) released per minute under experimental conditions. A standard curve was constructed using glucose concentrations of $0.625-10 \mathrm{mM}$ from which eventual IU values were calculated.
Optimum $\mathrm{pH}$ and temperature conditions were determined using assays that were all conducted with $50 \mathrm{mM}$ sucrose in $50 \mathrm{mM}$ citrate-phosphate buffers of different $\mathrm{pH}(3.0-7.0)$ and at different temperatures $\left(35-69^{\circ} \mathrm{C}\right)$. For the thermostability test, the enzyme samples were preincubated at different temperatures $\left(35-60^{\circ} \mathrm{C}\right.$, in $5^{\circ} \mathrm{C}$ increments) at $\mathrm{pH} 6.0$ for a set period of time after which similar DNS-based assays were conducted as described earlier. For the determination of kinetic parameters, sucrose concentrations that ranged from $3 \mathrm{mM}$ to $50 \mathrm{mM}$ were used. $K_{\mathrm{m}}$ and $V_{\max }$ estimations were determined by nonlinear regression analysis of velocity versus substrate concentration plots, using the Solver function of Microsoft Excel [40]. To determine the influence of different metal ions on invertase activity, assays were conducted using purified enzyme with two different concentrations of metal solution ( 5 and $50 \mathrm{mM}$ ) and were compared to the control i.e. with no metal ions present in the sucrose solution. Assays for recombinant fopA were conducted similarly as described above, but at its optimal conditions of $68^{\circ} \mathrm{C}$ at $\mathrm{pH}$ 5.0.

Enzyme assays destined for scFOS analyses for both CmINV and fopA were conducted at $40^{\circ} \mathrm{C}$ in $50 \mathrm{mM}$ citrate-phosphate buffer $\mathrm{pH}$ 6.0. Five-hundred microliters of crude extract of $S$. cerevisiae BY4742[CmINV] and BY4742[fopA] (appropriately diluted to equate to one IU of enzyme) were added to $500 \mu \mathrm{L}$ of $10 \% \mathrm{v} / \mathrm{v}$ $(0.29 \mathrm{M})$ sucrose and incubated for 60 minutes. The assay reaction was terminated by adding perchloric acid up to $2 \%(\mathrm{v} / \mathrm{v})$. After adding $48 \mu \mathrm{L}$ of $7 \mathrm{~N} \mathrm{KOH}$, samples were filtered through a $0.22 \mu \mathrm{m}$ syringe filter and were analysed for scFOS production. The fructosyltransferase activity $\left(\mathrm{U}_{\mathrm{t}}\right)$ and hydrolysis activity $\left(\mathrm{U}_{\mathrm{h}}\right)$ were measured from the amounts of scFOS and glucose, respectively.

\section{High-performance anion exchange chromatography with pulsed amperometric detection (HPAEC-PAD)}

Samples $(10 \mu \mathrm{l})$ were analysed on a Dionex Ultimate 3000 system equipped with a Coulochem III electrochemical detector with working gold electrode operating in the pulsed amperometric mode. HPLC-grade standards for L-arabinose, D-glucose, D-fructose and D-sucrose were purchased from Sigma-Aldrich. L-arabinose served as an internal standard. The fructooligosaccharide set (1-kestose, 1-nystose and $1^{\mathrm{F}}$-fructofuranosylnystose) was purchased from Wako Chemicals $\mathrm{GmbH}$. Mobile phases were made using sodium acetate (Sigma-Aldrich, cat. no.: 71180 ) and $50 \% \mathrm{NaOH}$ solution (Fluka, cat. no.: $71686)$ according to recommendations by Dionex. Ultrapure $18 \mathrm{M} \Omega$ deionized water used in experiments was obtained from a Milli-Q UF Plus system (Millipore). Separation of sugars was achieved by gradient elution on a CarboPac PA1 $(4 \times 250 \mathrm{~mm})$ analytical column 
coupled to a PA1 $(4 \times 50 \mathrm{~mm})$ guard column. A LPG$3400 \mathrm{AB}$ pump generated the required gradients by mixing solvents A $(250 \mathrm{mM} \mathrm{NaOH}), \mathrm{B}(100 \mathrm{mM} \mathrm{NaOH}$ with $500 \mathrm{mM}$ sodium acetate) and $\mathrm{C}$ (water) according to the program described in Additional file 2: Table S1. The flow rate was set at $1 \mathrm{ml} / \mathrm{min}$. The PAD settings were for a quadruple-potential waveform [41] with a minor modification of the E3 pulse set at $600 \mathrm{mV}$ for $10 \mathrm{~ms}$. The assembly was controlled by a desktop computer running the Chromeleon 6.8 Chromatography Data System software. Sugars were identified and quantified by comparing the retention times and ratios of sample peak area to internal standard peak area to similar ratios determined for external standards.

\section{Electrophoresis and zymogram analyses}

Crude extract and purified protein samples were subjected to 10\% SDS-PAGE. Loading dye consisted of $60 \mathrm{mM}$ Tris- $\mathrm{HCl}$ (pH 6.8), 25\% glycerol, 2\% SDS, $14 \mathrm{mM} \beta$-mercaptoethanol and bromophenol blue and gels were run in Tris-glycine buffer $(25 \mathrm{mM}$ Tris- $\mathrm{HCl}$, $250 \mathrm{mM}$ glycine, $0.1 \%$ SDS). After electrophoresis, protein bands were visualized with a silver-stain procedure [42]. For zymogram analyses, after electrophoresis, gels were washed in $50 \mathrm{mM}$ citrate-phosphate buffer $\mathrm{pH} 6.0$ for 60 minutes to remove SDS. Gels were then incubated at $60^{\circ} \mathrm{C}$ in the presence of $50 \mathrm{mM}$ sucrose for 15 minutes. After removal of sucrose solution, gels were placed in a boiling $100 \mathrm{mM} \mathrm{NaOH}$ solution that contains $0.2 \%$ triphenyltetrazolium chloride (Sigma) [43]. Some protein samples were de- $N$-glycosylated overnight with the endoglycosidase PNGase F (New England Biolabs) according to the manufacturer's protocol, prior to SDS PAGE.

\section{Phylogenetic analyses}

The relationship between the CmINV and other known invertases was determined by making use of a previous phylogenetic analysis of the GH32 family [15]. The Ceratocystis CmINV sequence was manually added to an alignment for this protein family, which were obtained from Timothy Y. James (University of Michigan, Ann Arbor, MI, USA). The dataset was then subjected to phylogenetic analyses using maximum likelihood and Bayesian Inference approaches based on the models and parameters previously used [15].

\section{Nucleotide sequence accession number}

The nucleotide sequence reported here for $C m I N V$ has been deposited in GenBank database under accession number KF129393.

\section{Additional files}

\begin{abstract}
Additional file 1: (a) Superose size-exclusion chromatography profile of S. cerevisiae BY4742[CmINV] supernatant containing CmINV with invertase activity of each fraction. (b) silver-stained SDS-PAGE gel of pooled fractions (fraction 4 and 5).
\end{abstract}

Additional file 2: HPAEC-PAD method for the gradient for elution of sugars. Gradient mixing program for high-performance anion exchange chromatography (HPAEC-PAD).

\section{Abbreviations}

BLAST: Basic local alignment sequencing tool; bp: Base pair; DC: Detergent compatible; DNS: Dinitrosalicylic acid; EC: Enzyme class; FPLC: Fast protein liquid chromatography; GF: Sucrose; GF2: 1-Kestose; GF3: 1-Nystose; GF4: $1^{F}$-Fructofuranosylnystose; GH: Glycoside hydrolase; HPAEC: Highperformance anion exchange chromatography; HPLC: High-performance liquid chromatography; IU: International units; $K_{m}$ : Michaelis constant; LB: Luria Bertani; MW: Molecular weight; PAD: Pulsed amperometric detection; PDA: Potato dextrose agar; SC: Synthetic complete; scFOS: Shortchain fructooligosaccharides; $U_{h}$ : Hydrolase activity; $U_{t}$ : Transferase activity; $V_{\text {max }}$ : Maximal reaction velocity.

Competing interests

The authors declare that they have no competing interests.

\section{Authors' contributions}

The NWW and KMT conducted all cloning experiments. NWW purified and characterized the CmINV protein. KMT did all the HPAEC analyses. KMT, BDW, ETS, HV conducted all the bioinformatic work including the phylogeny. NWW drafted the manuscript. All authors contributed in revising the initial draft. All authors read and approved the final version.

\section{Acknowledgements}

The authors would like to thank Craig Adriaanse and Stefan Hayward, Department of Biochemistry, University of Stellenbosch, for their assistance with the Äkta FPLC purifier. NWW was funded by the Claude Leon Foundation Postdoctoral Fellowship. KMT is a L'Oreal-UNESCO for Women in Science in sub-Saharan Africa Regional Fellowship-2011 awardee.

\section{Author details}

'Department of Microbiology, Stellenbosch University, Room A322, JC Smuts Building, De Beer Street, Private Bag X1, Matieland 7602 Stellenbosch, South Africa. ${ }^{2}$ Department of Microbiology and Plant Pathology, Forestry and Agricultural Biotechnology Institute, University of Pretoria, Pretoria, South Africa.

Received: 6 August 2013 Accepted: 11 November 2013 Published: 14 November 2013

\section{References}

1. Myrbäck K: Studies on yeast invertase. Soluble and insoluble invertase (saccharase) of baker's yeast. Arch Biochem Biophys 1957, 69:138-148.

2. Hidaka H, Hirayama M, Sumi N: A fructooligosaccharide-producing enzyme from Aspergillus niger ATCC 20611. Agr Biol Chem Tokyo 1988, 52(5):1181-1187.

3. Manning TS, Gibson GR: Prebiotics. Best Pract Res Cl Ga 2004, 18(2):287-298.

4. Teitelbaum J, Walker W: Nutritional impact of pre- and probiotics as protective gastrointestinal organisms. Annu Rev Nutr 2002, 22:107-138.

5. Su J, Xu J, Chen Y, Xiang Y, Yuan R, Chai Y: Personal glucose sensor for point-of-care early cancer diagnosis. Chem Commun 2012, 48(55):6909-6911.

6. Xiang Y, Lu Y: Using personal glucose meters and functional DNA sensors to quantify a variety of analytical targets. Nature Chem 2011, 3(9):697-703.

7. Cantarel BI, Coutinho PM, Rancurel C, Bernard T, Lombard V, Henrissat B. The carbohydrate-active EnZymes database (CAZy): an expert resource for glycogenomics. Nucleic Acids Res 2009, 37(1):D233-D238.

8. Pons T, Naumoff DG, Martínez-Fleites $C$, Hernández L: Three acidic residues are at the active site of a $\beta$-propeller architecture in glycoside hydrolase families 32, 43, 62, and 68. Proteins Struct Funct Genet 2004, 54(3):424-432. 
9. Alberto F, Bignon C, Sulzenbacher G, Henrissat B, Czjzek M: The threedimensional structure of invertase ( $\beta$-fructosidase) from Thermotoga maritima reveals a bimodular arrangement and an evolutionary relationship between retaining and inverting glycosidases. $\mathrm{J} \mathrm{Biol} \mathrm{Chem}$ 2004, 279(18):18903-18910.

10. Álvaro-Benito M, Polo A, González B, Fernández-Lobato M, Sanz-Aparicio J: Structural and kinetic analysis of Schwanniomyces occidentalis invertase reveals a new oligomerization pattern and the role of its supplementary domain in substrate binding. J Biol Chem 2010, 285(18):13930-13941.

11. Maiorano AE, Piccoli RM, Silva ES, Andrade Rodrigues MF: Microbial production of fructosyltransferases for synthesis of pre-biotics. Biotechnol Lett 2008, 30(11):1867-1877.

12. Yanai K, Nakane A, Kawate A, Hirayama M: Molecular cloning and characterization of the fructooligosaccharide-producing $\beta$ fructofuranosidase gene from Aspergillus niger ATCC 20611. Biosci Biotechnol Biochem 2001, 65(4):766-773.

13. Zuccaro A, Götze S, Kneip S, Dersch P, Seibel J: Tailor-made fructooligosaccharides by a combination of substrate and genetic engineering. Chem Bio Chem 2008, 9(1):143-149.

14. Kurakake M, Ogawa K, Sugie M, Takemura A, Sugiura K, Komaki T: Two types of $\beta$-fructofuranosidases from Aspergillus oryzae KB. J Agr Food Chem 2007, 56(2):591-596.

15. Parrent J, James $T$, Vasaitis $R$, Taylor A: Friend or foe? evolutionary history of glycoside hydrolase family 32 genes encoding for sucrolytic activity in fungi and its implications for plant-fungal symbioses. BMC Evol Biol 2009, $9(1): 148$.

16. Goosen C, Yuan XL, van Munster JM, Ram AF, van der Maarel MJ, Dijkhuizen $L$ : Molecular and biochemical characterization of a novel intracellular invertase from Aspergillus niger with transfructosylating activity. Eukaryot Cell 2007, 6(4):674-681

17. Yun JW: Fructooligosaccharides: occurrence, preparation, and application. Enzym Microb Technol 1996, 19(2):107-117.

18. Bañuelos $\mathrm{O}$, del Carmen Ronchel M, Adrio JL, Velasco J: Screening of microorganisms for enzymatic biosynthesis of nondigestible oligosaccharides. In Microbial Enzymes and Biotransformations, Volume 17. Edited by Barredo JL. New Jersey: Humana Press; 2005:105-113.

19. Arruda $L M O$, Vitolo M: Characterization of invertase entrapped into calcium alginate beads. App/ Biochem Biotechnol 1999, 81(1):23-33.

20. Goldstein A, Oliver Lampen j, Wood WA: $\beta$-Fructofuranoside fructohydrolase from yeast. Methods Enzymol 1975, 42:504-511.

21. Sanjay G, Sugunan S: Enhanced pH and thermal stabilities of invertase immobilized on montmorillonite K-10. Food Chem 2006, 94(4):573-579.

22. Lafraya A, Sanz-Aparicio J, Polaina J, Marín-Navarro J: Fructo-oligosaccharide synthesis by mutant versions of Saccharomyces cerevisiae invertase. Appl Environ Microbiol 2012, 77(17):6148-6157.

23. Tananchai $P$, Yusuf $C$ : Stabilization of invertase by molecular engineering. Biotechnol Progr 2010, 26(1):111-117.

24. Menéndez C, Martínez D, Trujillo LE, Mazola Y, González E, Pérez ER, Hernández L: Constitutive high-level expression of a codon-optimized $\beta$-fructosidase gene from the hyperthermophile Thermotoga maritima in Pichia pastoris. Appl Microbiol Biotechnol 2012, 97(3):1-12

25. Kotwal SM, Shankar V: Immobilized invertase. Biotechnol Adv 2009, 27(4):311-322.

26. Guimarães LHS, Somera AF, Terenzi HF, Polizeli MLTM, Jorge JA: Production of $\beta$-fructofuranosidases by Aspergillus niveus using agroindustrial residues as carbon sources: characterization of an intracellular enzyme accumulated in the presence of glucose. Process Biochem 2009, 44(2):237-241.

27. Rustiguel CB, Terenzi HF, Jorge JA, Guimarães LHS: A novel silver-activated extracellular $\beta$-D-fructofuranosidase from Aspergillus phoenicis. J Mol Catal B Enzym 2010, 67:10-15.

28. Dominy BN, Perl D, Schmid FX, Brooks CL: The effects of ionic strength on protein stability: the cold shock protein family. J Mol Biol 2002, 319(2):541-554.

29. Rubio MAC, Runco R, Navarro AR: Invertase from a strain of Rhodotorula glutinis. Phytochemistry 2002, 61(6):605-609.

30. Gustafsson C, Minshull J, Govindarajan S, Ness J, Villalobos A, Welch M: Engineering genes for predictable protein expression. Protein Express Purif 2012, 83(1):37-46.

31. Welch M, Villalobos A, Gustafsson C, Minshull J, Christopher V: Designing genes for successful protein expression. Method Enzymol 2010, 498:43-66.
32. Sambrook J, Fitsch EF, Maniatis T: Molecular cloning: A laboratory manual. 2nd edition. Cold Spring Harbor, New York: Cold Spring Harbor Laboratory Press; 1989.

33. Kelly D, Lamb D, Kelly S: Genome-wide generation of yeast gene deletion strains. Comp Funct Genomics 2001, 2(4):236-242.

34. Winzeler EA, Shoemaker DD, Astromoff A, Liang H, Anderson K, Andre B, Bangham R, Benito R, Boeke JD, Bussey $H$, et al: Functional characterization of the $S$. cerevisiae genome by gene deletion and parallel analysis. Science 1999, 285(5429):901-906.

35. Stanke M, Diekhans M, Baertsch R, Haussler D: Using native and syntenically mapped cDNA alignments to improve de novo gene finding. Bioinformatics 2008, 24(5):637-644.

36. Hoffman CS, Winston F: A ten-minute DNA preparation from yeast efficiently releases autonomous plasmids for transformation of Escherichia coli. Gene 1987, 57(2):267-272

37. Crous JM, Pretorius IS, Van Zyl WH: Cloning and expression of an Aspergillus kawachii endo-1,4- $\beta$-xylanase gene in Saccharomyces cerevisiae. Curr Genet 1995, 28(5):467-473.

38. Hill J, Donald KAIG, Griffiths DE: DMSO-enhanced whole cell yeast transformation. Nucleic Acids Res 1991, 19(20):5791.

39. Miller $G L$ : Use of dinitrosalicylic acid reagent for determination of reducing sugar. Anal Chem 1959, 31(3):426-428.

40. Fylstra D, Lasdon L, Watson J, Waren A: Design and use of the Microsoft excel solver. Interfaces 1998, 28(5):29-55.

41. Rocklin RD, Clarke AP, Weitzhandler M: Improved long-term reproducibility for pulsed amperometric detection of carbohydrates via a new quadruple-potential waveform. Anal Chem 1998, 70(8):1496-1501.

42. Gallagher SR, Sasse J: Staining proteins in gels. Curr Protoc Essential Lab Tech 2012, 6:1-7.

43. Chaira N, Smaali I, Besbes S, Mrabet A, Lachiheb B, Ferchichi A: Production of fructose-rich syrups using invertase from date palm fruits. J Food Biochem 2011, 35(6):1576-1582

doi:10.1186/1472-6750-13-100

Cite this article as: van Wyk et al:: Identification of the Gene for $\beta$-Fructofuranosidase from Ceratocystis moniliformis CMW 10134 and characterization of the enzyme expressed in Saccharomyces cerevisiae. BMC Biotechnology 2013 13:100.

\section{Submit your next manuscript to BioMed Central and take full advantage of:}

- Convenient online submission

- Thorough peer review

- No space constraints or color figure charges

- Immediate publication on acceptance

- Inclusion in PubMed, CAS, Scopus and Google Scholar

- Research which is freely available for redistribution

Submit your manuscript at www.biomedcentral.com/submit
C) Biomed Central 